\title{
Subject Usage and Funding of Library Monographs
}

\section{Joe Crotts}

\begin{abstract}
This investigation seeks to identify those variables that prove indicative of the demand for monographs by subject and to develop a practical method for allocating funding by subject that realistically reflects subject demand. The interrelationships among circulation, expenditure, and enrollment by subject are analyzed. Circulation is isolated as the single empirically supported parameter upon which the demand for monographs by subject may be measured. A model for allocating subject funding is developed.
\end{abstract}

A good formula would help guarantee that available book funds will be distributed efficiently and equitably, that departments will be properly funded. ${ }^{1}$

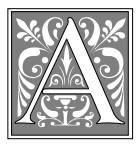

cademic libraries experienced a proliferation of new periodicals accompanied by radically escalating subscription rates throughout the 1980s and into the early 1990s. Institutions responded from within by conducting intensive assessments of periodical usage and expenditure, subsequently proceeding to massive cancellations. The literature is replete with survey techniques and formulae for assessing usage of periodical titles by subject and, correspondingly, the allocation of funds by subject for periodicals. The publishing industry, albeit slow to realize the definitiveness of the library dollar, is responding by repackaging periodical literature into electronic formats. Resolving what appeared to entail an insurmountable task several years ago today appears more manageable as a desirable by-product of the massive transition of periodical literature into electronic format and subsequent networking into comprehensive, multititle, and multidisciplinary partial and full-text CDROM, and, increasingly, online electronic resources. Technology, thank you!

Monographs, however, have not received such favorable acceptance by the new technology. Electronic packaging has been slow to emerge, and, predictably, the book, in its present physical form, will remain the mainstay of academic library collections for the remainder of the twentieth century. "On the whole ... current books are simply not now available electronically. Nor will see all the titles already in print on line someday ... we are still not even close to having the critical mass of information available on line that is necessary to support faculty or even student research." ${ }^{2}$

Major funding outlay for monographs will continue to encumber large portions of collection budgets. With escalating monograph prices exceeded only by the continued shrinkage of the library book budget, and both topping the rate of inflation, it becomes increasingly imperative that every

Joe Crotts is Access Services Librarian in Meriam Library at California State University, Chico; email: jcrotts@csuchico.edu. 
dollar expended be directed at ensuring maximum return as a resource in demand.

\section{The State of Research}

Unfortunately, empirical investigation into technique and formulae for assessing subject usage and allocating funds for monograph collection development has lagged far behind similar emphases placed on periodical literature. Tradition remains prevalent. The time-honored practice of allocating funds in relative proportion to academic department size, measured almost invari-

\section{Departmental allocations for mono- graphs almost invariably reflect anticipated behavior.}

ably in terms of faculty number, continues to dominant methodology for determining department "book budgets." Ostensibly, departments with more numerous faculty receive larger allocations. This single factor overwhelmingly predominates over all other and related criteria, and has seldom undergone serious challenge. The substitution of subject circulation, a variable of significantly greater consequence, has received only minimal acceptance as the primary weighted factor in determining departmental monograph allocations.

Departmental allocations for monographs almost invariably reflect anticipated behavior. We presume that a department with a large number of faculty has achieved that magnitude in response to supporting a large number of students, who will, in turn, place a correspondingly and proportionately heavy demand on the monograph collection.

The expenditure of these funds, however, should ideally reflect actual behavior. "Seldom does anticipated match actual behavior in a complex social structure, and the academic library is no exception." " "One must consider a number of factors such as past practices, differential publication and inflation rates, level of demand, and actual use." ${ }^{4}$ And here lies the crux of the matter. The level of demand, best reflected as a measure of actual usage of materials, is all too frequently a poor indicator of department size. A large department may not generate heavy library usage. Conversely, smaller departments may well generate heavy library usage. Consequently, tradition in practice does not uniformly hold true in application. Ignored, as is all to often the case, it takes the effect of large allocations being assigned to some large departments that generate relatively little demand on monographic usage. Conversely, small departments generating intense monographic usage may receive small allocations with which to purchase what inevitably become resources in very high demand.

Previous attempts to quantify the demand for monographs in differing subjects have relied heavily on the inclusion of artificially (qualitatively) derived weighted factors designed to introduce a measure of "hardness" to the intellectual organization and content of the subject. ${ }^{5}$ Similar attempts have incorporated preconceived notions of thresholds and optimal magnitudes of total monographs or monographs per student and the assignment of variables of arbitrary weights derived from "judgment based on experience and the librarian's own knowledge of his [or her] own library." ${ }^{\prime \prime, 7}$ Such variables tend to drive the formula toward nonstatistically supported results rather than support an accurate representation of actual usage of monographs by subject. These and related nonstatistically derived variables have tended to weigh heavily (if not disproportionately so) in calculations, and have thus rendered formulae for determining subject allocations to poorly reflect what they probably should most be indicative of-actual usage of materials.

Resolving the issue entails one to inquire, how can actual behavior (monographic usage) be predicted in terms sufficiently accurate to exert an equitable influence over magnitude of departmental monograph allocations? Simply put, how can we better measure usage so as to better determine departmental book budgets?

One might expect that ... over the many years ... librarians would have made considerable progress in defin- 
ing the values, methods, scope, and the purposes of collection evaluation. But such is not the case. ${ }^{8}$

Twenty variables with potential and probable consequence in collection evaluation were identified in $1941 .^{9}$ Subsequent efforts directed at relating selected individual and groups of these variables to derive meaningful and practical methods of collection evaluation have met with little success and have received sporadic acceptance at best. Results tend to be decidedly inconclusive. "No formulas, magic or otherwise, result." 10 "The attempt to identify and weigh the factors which affect the need for books in academic situations reveals gaps in our knowledge, to the filling of which research might profitably be directed. The difficulty arises simply from the quantity of detail and number of variables involved."11

Achieving a viable solution to these problems eludes practitioners to this very day.

\section{Clearly libraries support a large base of users ... How then is it possible to know when collections are at least ad- equate to meet campus needs? By what criteria might librarians deter- mine the adequacy of the collections they are responsible for building in relation to the audience that the col- lection is to support? ${ }^{12}$}

\section{Goals of the Study}

The goals of this study are to identify those variables that may serve to reflect the relative demand for monographs by subject and to develop a realistic and practical method for allocating funding by subject. Proceeding on the premise that the "pot" of money at one's disposal is finite in the sense that an overall total applies collectively to all subjects, the solution entails determining the relative proportion of funding appropriate to meet the demand for each subject.

\section{The Study Site}

California State University, Chico, served as the sample for the study. The university enrolls approximately 12,000 students. Un- dergraduate degrees are offered in fiftyseven disciplines, including most areas of the humanities, social sciences, engineering, and technology. Master's degrees are offered in twenty-nine of these disciplines. The campus is largely residential and is the only comprehensive institution of higher education in a vast rural area. Students and faculty depend entirely on the resources of the university library, as no other comprehensive academic or public libraries are located within a hundred-mile radius.

\section{The Data}

Data were collected from the five-year period from 1990 to 1995 . Annual averages were calculated and manipulated in the analyses. Individual subjects, generally but not exclusively, corresponding to academic departments, serve as the basic unit upon which data are organized. Three subject areas - medicine, architecture, and photography-in which the university does not offer degrees were included in analyses not involving enrollment.

The analysis centers on the interrelationships of these subject data. Components of subject data used in the analysis include expenditure, enrollment, and circulation. Subject enrollment is reported in terms of FTE (full-time enrolled student); that is, the total units (hours) divided by fifteen. Subject expenditure includes the "departmental" allocation, together with expenditure encumbered by books received though the approval plan. Circulation includes initial checkouts and renewals.

\section{Analysis of the Data \\ Relationship between Expenditure and Circulation}

The correlation between expenditure and circulation is weak. Circulation of books in a subject does not consistently reflect the amount of money encumbered for books in that subject. Fewer than 30 percent of subjects, primarily in the humanities and social sciences, are proportionately related. Greater expenditure tends to reflect greater circulation for most of the humanities and social sciences. However, very negative correlations exist between the physical sciences 
and business areas. Most physical sciences and business show circulation much lower than the relative expenditure for books in these subjects (see figure 1).

In highly generalized terms, circulation may be defined as a function of expenditure by the equation:

$$
\mathrm{C}=0.6 \mathrm{E}-3000
$$

where: $\mathrm{C}=$ circulation

$$
\mathrm{E}=\text { expenditure (in dollars). }
$$

Overall, the relationship is extremely generalized and of limited value for planning monetary allocations for books by subject. Subject expenditure does not necessarily reflect circulation of books in that subject (see figure 2).

\section{Relationship between Enrollment and Circulation}

The correlation between enrollment and circulation is even weaker than the correlation between expenditure and circulation. Circulation of books in a subject seldom reflects the level of enrollment in that subject. Fewer than 30 percent of subjects are proportionately related, with extreme disparities noted in the physical sciences and business, as well as several areas of the social sciences. In general, the mediumsized departments generate the most circulation. However, the overall relationship cannot be even loosely defined by an equation. Subject enrollment cannot serve as an indicator of circulation of books in that subject (see figures 3 and 4 ).

\section{Combining the Variables: Expenditure, Circulation, Enrollment}

Ideally, horizontal lines would connect the hierarchy of subjects under the three variables, indicating a logical, balanced, and progressive relationship between expendi-

\begin{tabular}{c} 
FIGURE 1 \\
Expenditure - Circulation \\
\hline \hline
\end{tabular}

1990-1995 Mean Annual Expenditure and Circulation

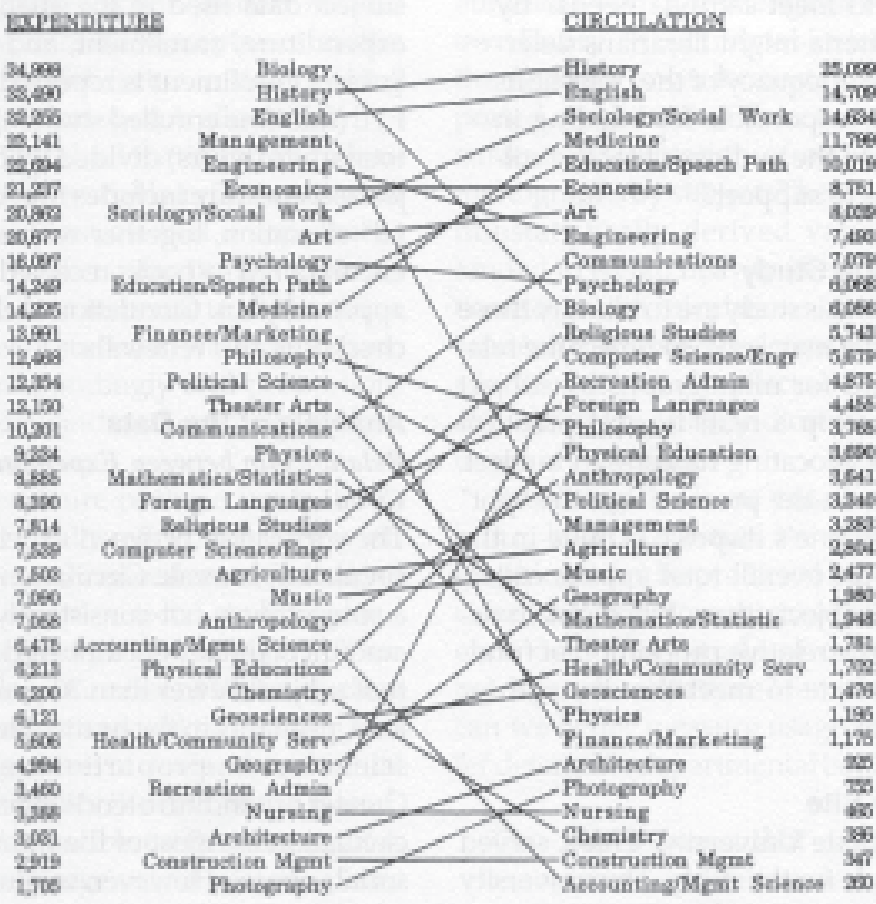


FIGURE 2

The Relationship of Expenditure to Circulation

1990-1995 Mean Annual Expenditure and Circulation by Subject.

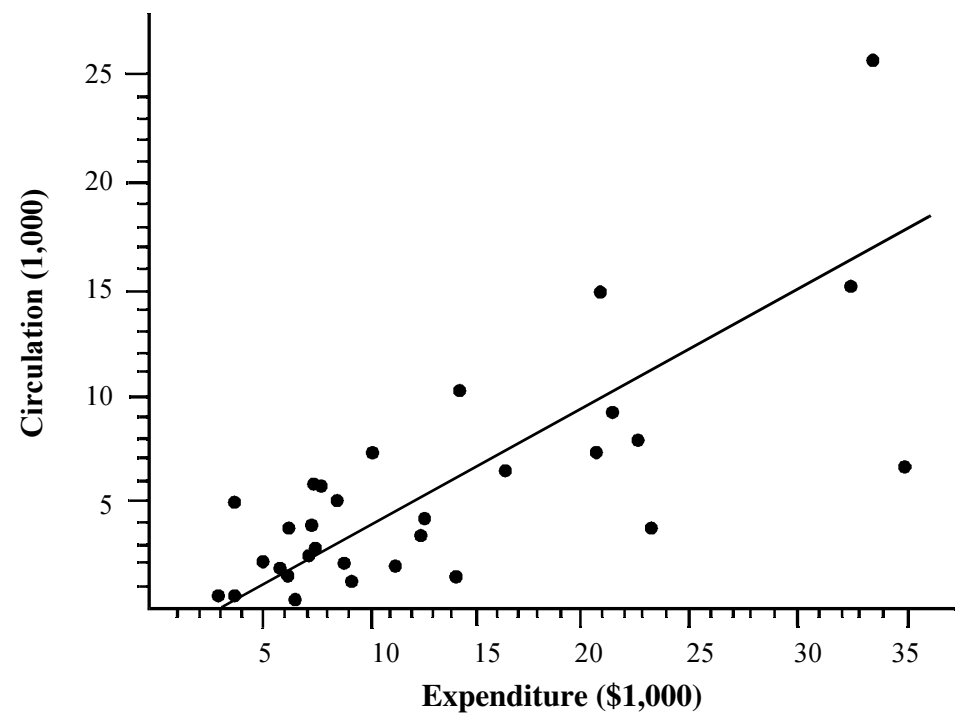

ture, enrollment, and circulation (see figure 5). However, the combined effect of expenditure and enrollment is proportionately related to circulation in fewer than 10 percent of subjects. Circulation appears to be a variable largely independent of expenditure and enrollment, taken individually and together. Business areas display the extreme cases, with low circulation, but high expenditure and enrollment. Subject circulation is not indicative of expenditure for books and/or enrollment in subjects.

\section{Circulation Anomalies}

The relationship of circulation to expenditure and enrollment is characterized by numerous minor and major anomalies. These may be broadly grouped into four categories, ranging from high circulation and low expenditure with high or low enrollment to low circulation and high expenditure with high and low enrollment. Adjustments in expenditure to balance the relationships are suggested (see table 1).

\section{“Cost”of Circulation}

The anomalies in the relationship of circulation to expenditure and enrollment gen- erate a set of values that may be considered in measuring the "cost" of circulating books. The values represent a tangible indication of return on the dollar for usage of books by subject. The cost of circulation may be realized in terms of the dollars expended per book circulated, or the number of books circulated per dollar expended. Values for dollars expended per book range from less than one dollar (recreation) to almost twenty-five dollars (accounting). Values increase quite uniformly, with the exception of extremely large increases for the three most "expensive" subjects-finance, chemistry, and accounting. Excluding these three subjects, the average falls to $\$ 3.26$. The overall median is only $\$ 2.67$, which is much more indicative of the overall cost of circulating books.

A similar pattern in reverse prevails for the number of books circulated for each dollar in expenditure. Values in terms of books circulated per dollar average 0.41, and range from a high of 1.41 for recreation to a low of 0.0 .4 for accounting. Values decrease quite uniformly throughout the range, as shown in table 2 .

The most expensive subjects to circulate 


\section{FIGURE 3}

Enrollment - Circulation

1990-1995 Mean Annual Circulation and Enrollment (Full Time Equivalent).

\section{ENROLLMENT FTE! CIRCULATION}

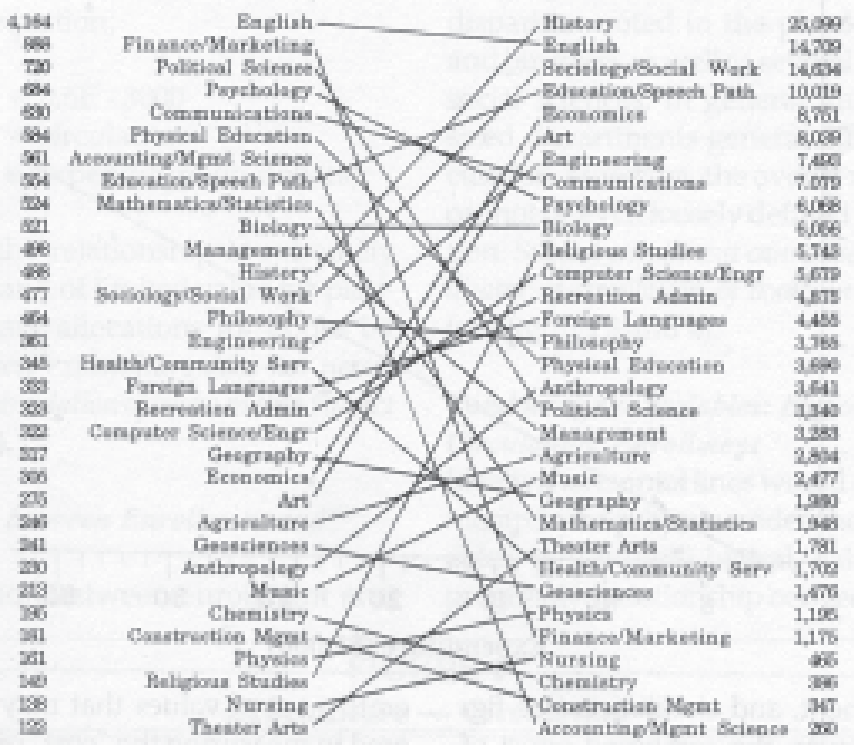

FIGURE 4

The Relationship of Enrollment to Circulation

1990-1995 Mean Annual Enrollment (Full Time Equivalent) and Circulation by

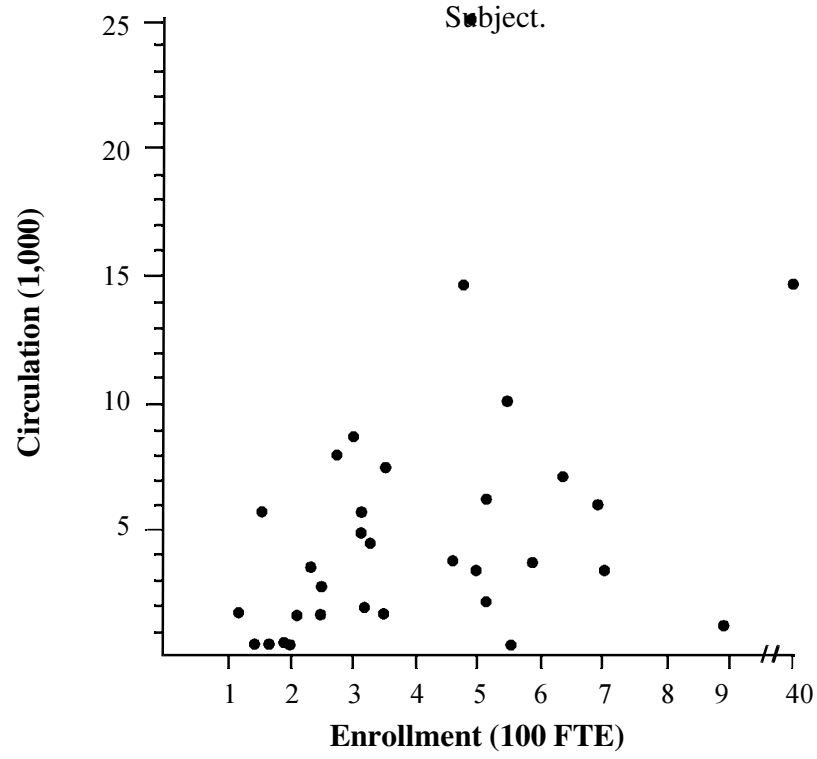




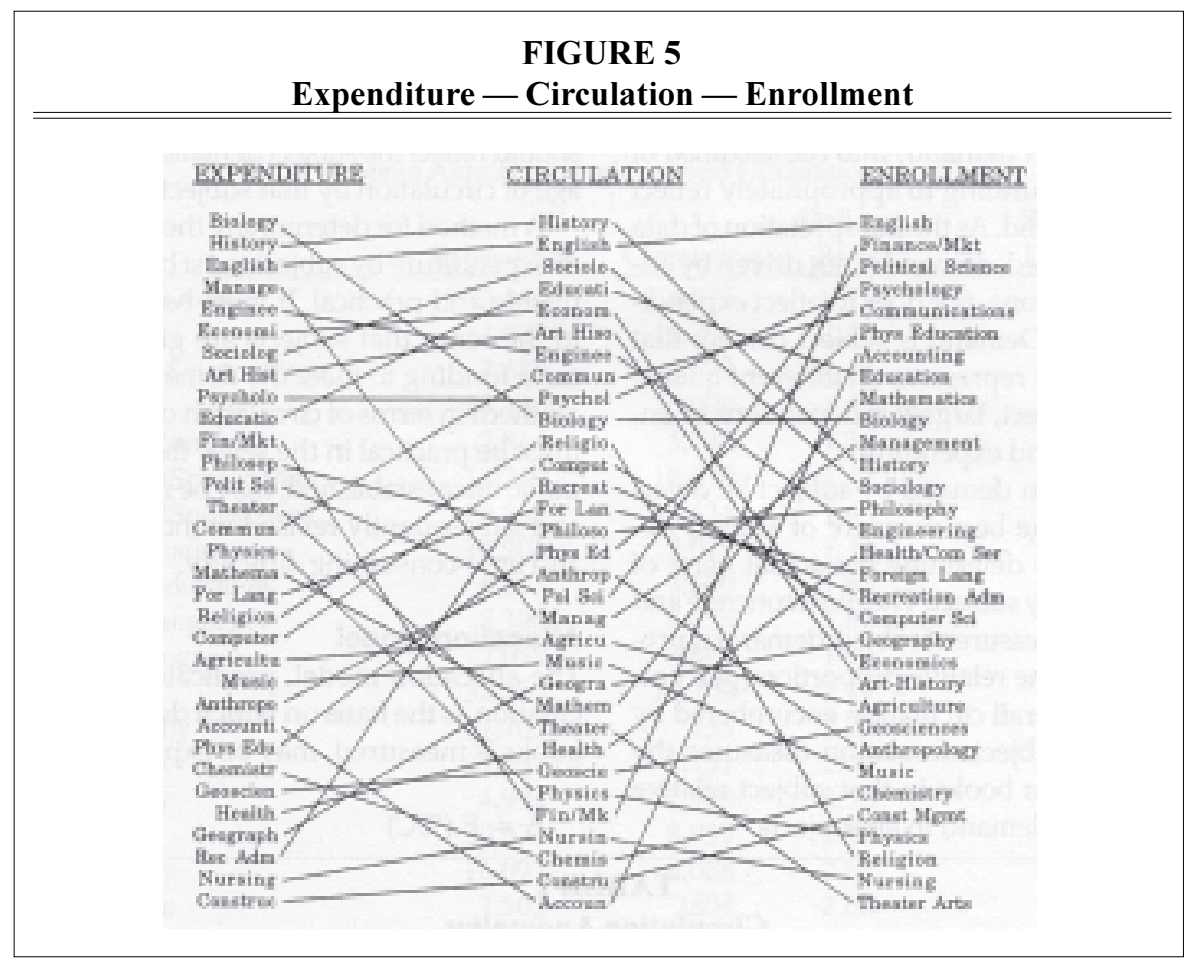

fall primarily within the sciences, business, and technology, with the notable inclusion of theater arts. The less expensive subjects include a combination of social sciences, humanities, medicine, and computer science.

The cost of circulation falls below the overall average of $\$ 4.49$ for 71 percent of subjects. Fifty-four percent of subjects fall below $\$ 3.00$ per book, with the largest group of subjects $(31 \%)$ circulating within the one dollar range and below. The cost of circulation for books in the majority of subjects falls below $\$ 3.00$ per book, and well below the average of $\$ 4.49$.

In terms of number of books circulated:

- ninety percent circulated at costs below $\$ 4.00$ per book;

- eighty percent circulated at costs below $\$ 3.00$ per book;

- fifty-five percent circulated at costs below $\$ 2.00$ per book.

Books circulating at costs exceeding $\$ 4.00$ per book comprised only 10 percent of overall circulation, and primarily included books in sciences and business.

The majority of books in most of the subjects circulate at costs well below the average.

\section{Ratio of Expenditure to Circulation}

The ratio of subject expenditure to subject circulation yields a cost/usage value that may be considered a relative measure of "bang for the buck" for each subject. Values increase quite uniformly, ranging from 0.1 (chemistry) to 3.0 (recreation), with a mean of 1.0. Books in subjects with values above and below 1.0 are increasingly less costly or more costly to circulate. The values yield an indication of the relative strength of the dollar in terms of (circulation) demand for books. Adjustments in the hierarchy would entail decreasing funds allocated to books with low rations and shifting them upward to subjects with high circulation in relation to expenditure and, it is hoped, would have the effect of positioning funds where demand for more funding is greater. As an obvious example, the funding for chemistry might be reduced and the remainder reallocated to recreation, where a need for more books may well be evidenced by the very high circulation in relation to expenditure (see table 3). 


\section{A Model for Subject Allocation}

The major objective of an allocation model is to translate the demand for books by subject (subject demand) into the allocation of sufficient funding to appropriately reflect that demand. As the interpretation of data has indicated, demand is not driven by enrollment alone, nor does it reflect expenditure well. Demand is subject driven; that is, demand represents an inherent quality of the subject, largely independent of enrollment and expenditure.

How can demand by subject be determined? The best measure of subject demand is to determine the actual usage of materials by subject. The most concrete and practical measure of subject demand is provided by the relative proportion (percentage) of overall circulation encumbered by subject. Subject circulation measures the demand for books in that subject relative to overall demand in all subjects.
How can subject demand be translated into subject expenditure? Subject expenditure, the expenditure allocated by subject, should reflect the subject demand (percentage of circulation by that subject).

A method for determining the allocation of expenditure by subject must be both equitable and practical. It must be equitable in the sense that subjects are given sufficient funding to meet the demand placed on them in terms of circulation of books. It must be practical in the sense that the formula, once established, may be monitored and subsequently revised without undue and time-consuming difficulty.

\section{Allocation Model}

The allocation model, predicated on circulation as the basis on which demand for books is measured, may be expressed as:

$$
\mathrm{A}=\mathrm{E}(\% \mathrm{C})
$$

\begin{tabular}{|c|c|c|c|c|c|c|}
\hline \multicolumn{7}{|c|}{$\begin{array}{c}\text { TABLE } 1 \\
\text { Circulation Anomalies } \\
\end{array}$} \\
\hline & \multicolumn{2}{|c|}{ Circulation } & \multicolumn{2}{|c|}{ Enrollment } & \multicolumn{2}{|c|}{ Expenditure } \\
\hline Department & Low & High & Low & High & Low & High \\
\hline \multicolumn{7}{|l|}{1} \\
\hline \multicolumn{2}{|l|}{ Recreation } & • & - & & - & \\
\hline \multicolumn{2}{|l|}{ Computer Science } & $\bullet$ & $\bullet$ & & $\bullet$ & \\
\hline \multicolumn{2}{|l|}{ Religion } & $\bullet$ & • & & $\bullet$ & \\
\hline \multicolumn{2}{|l|}{ Sociology } & $\bullet$ & $\bullet$ & & $\bullet$ & \\
\hline \multicolumn{2}{|l|}{ Anthropology } & $\bullet$ & $\bullet$ & & $\bullet$ & \\
\hline \multicolumn{2}{|l|}{2} & & & & & \\
\hline \multicolumn{2}{|l|}{ Geography } & $\bullet$ & & $\bullet$ & $\bullet$ & \\
\hline \multicolumn{2}{|l|}{ Health } & - & & - & $\bullet$ & \\
\hline \multicolumn{2}{|l|}{ Phys Ed } & $\bullet$ & & - & • & \\
\hline \multicolumn{2}{|l|}{$\overline{3}$} & & & & & \\
\hline Management & • & & & $\bullet$ & & - \\
\hline Finance & - & & & $\bullet$ & & $\bullet$ \\
\hline Math & • & & & - & & - \\
\hline Acct/Mgmt Science & $\bullet$ & & & - & & - \\
\hline \multicolumn{7}{|l|}{4} \\
\hline Theater & • & & • & & & $\bullet$ \\
\hline Physics & $\bullet$ & & • & & & $\bullet$ \\
\hline Chemistry & • & & $\bullet$ & & & $\bullet$ \\
\hline \multicolumn{7}{|c|}{ Expenditure Adjustment to Balance Use - Enrollment - Expenditur } \\
\hline \multicolumn{7}{|c|}{$\begin{array}{l}\text { Expenditure Aajustment to balance Use-Enroiment - Expenaitu } \\
\text { Group 1. Increase }\end{array}$} \\
\hline \multicolumn{7}{|c|}{ Group 2. Increase substantially } \\
\hline \multicolumn{7}{|c|}{ Group 3. Decrease } \\
\hline \multicolumn{7}{|c|}{ Group 4. Decrease substantially } \\
\hline
\end{tabular}


TABLE 2

The "Cost" of Circulation

1990-1991 Mean Annual Expenditure and Circulation by Subject

\begin{tabular}{|c|c|c|c|c|}
\hline Subject & Expenditure & Circulation & $\begin{array}{c}\text { Dollars/ } \\
\text { Book }\end{array}$ & $\begin{array}{l}\text { Books/ } \\
\text { Dollar }\end{array}$ \\
\hline Recreation Admin. & 3,460 & 4,875 & 0.71 & 1.41 \\
\hline Medicine & 14,225 & 11,799 & 1.21 & 0.83 \\
\hline Computer Science/Engr. & 7,539 & 5,679 & 1.33 & 0.75 \\
\hline History & 33,490 & 25,099 & 1.33 & 0.75 \\
\hline Religious Studies & 7,814 & 5,743 & 1.36 & 0.73 \\
\hline Education/Speech Path & 14,249 & 10,019 & 1.42 & 0.82 \\
\hline Sociology/Social Work & 20,862 & 14,634 & 1.43 & 0.70 \\
\hline Communications & 10,201 & 7,079 & 1.44 & 0.69 \\
\hline Physical Education & 6,213 & 3,690 & 1.68 & 0.59 \\
\hline Foreign Languages & 8,390 & 4,455 & 1.88 & 0.53 \\
\hline Anthropology & 7,058 & 3,641 & 1.94 & 0.52 \\
\hline English & 32,255 & 14,709 & 2.19 & 0.46 \\
\hline Photography & 1,705 & 755 & 2.25 & 0.44 \\
\hline Economics & 21,237 & 8,751 & 2.43 & 0.41 \\
\hline Geography & 4,994 & 1,980 & 2.52 & 0.40 \\
\hline Art & 20,677 & 8,039 & 2.57 & 0.39 \\
\hline Psychology & 16,097 & 6,068 & 2.66 & 0.38 \\
\hline Agriculture & 7,503 & 2804 & 2.68 & 0.37 \\
\hline Music & 7,090 & 2,477 & 2.86 & 0.35 \\
\hline Engineering & 22,694 & 7,493 & 3.03 & 0.33 \\
\hline Architecture & 3,031 & 925 & 3.28 & 0.31 \\
\hline Health/Community Serv. & 5,606 & 1,702 & 3.29 & 0.30 \\
\hline Philosophy & 12,468 & 3,765 & 3.31 & 0.30 \\
\hline Political Science & 12,354 & 3,340 & 3.70 & 0.27 \\
\hline Geosciences & 6,121 & 1,476 & 4.15 & 0.24 \\
\hline Mathematics/Statistics & 8,885 & 1,948 & 4.56 & 0.22 \\
\hline Biology & 34,998 & 6,056 & 5.78 & 0.17 \\
\hline Theater Arts & 12,150 & 1,781 & 6.82 & 0.15 \\
\hline Management & 23,141 & 3,283 & 7.05 & 0.14 \\
\hline Physics & 9,234 & 1,195 & 7.73 & 0.13 \\
\hline Nursing & 3,388 & 465 & 7.29 & 0.14 \\
\hline Construction Mgmt & 2,919 & 347 & 8.41 & 0.12 \\
\hline Finance/Marketing & 13,981 & 1,175 & 11.90 & 0.08 \\
\hline Chemistry & 6,200 & 386 & 16.06 & 0.06 \\
\hline \multirow[t]{3}{*}{ Accounting/Mgmt. Science } & 6,475 & 260 & 24.90 & 0.04 \\
\hline & & Mean & 4.49 & 0.41 \\
\hline & & Median & 2.67 & 0.38 \\
\hline
\end{tabular}

where: $\mathrm{A}=$ subject allocation

$\mathrm{E}=$ overall expenditure

$\mathrm{C}=$ subject demand (percentage of overall circulation).

Rather than engage in the tedious chore of recalculating the subject demand annually, several years of data (e.g., 1990-1995) may be averaged and serve as the base demand. The base demand serves as the tool for which expenditure by subject is projected. After the total budget for purchasing monographs (excluding reference and interdisciplinary areas) is known, the subject (usually departmental) allocations can be easily calculated. Recalculations of subject demand may prove expedient every 
three to five years, and more often should major changes in curriculum occur.

Revised allocations, based on the base demand, differ significantly from previous allocations (see figure 6) and, it is hoped, represent a more realistic level of expenditure for materials in relation to usage.

The revised (base) allocations range from 14.1 percent (history) to 0.1 percent (accounting) of the overall budget for ex- penditure. The present allocations, not based on subject demand in terms of circulation, are confined to a narrower scale, ranging from 8.2 percent (biology) to 0.4 percent (photography).

Subject allocations generated from this model differ significantly from present expenditure, with contrasts ranging from plus 237 percent to minus 93 percent. The magnitude of change necessary in realigning

TABLE 3

Ratio of Expenditure to Circulation

1990-1995 Mean Annual Expenditure and Circulation

\begin{tabular}{|c|c|c|c|}
\hline Department & $\begin{array}{c}\% \\
\text { Expenditure }\end{array}$ & $\begin{array}{c}\% \\
\text { Circulation }\end{array}$ & $\begin{array}{l}\text { Circulation/ } \\
\text { Expenditure }\end{array}$ \\
\hline Recreation Administration & 0.9 & 2.7 & 3.0 \\
\hline Medicine & 3.3 & 6.6 & 2.0 \\
\hline Computer Science/Engineering & 1.8 & 3.2 & 1.8 \\
\hline History & 7.8 & 14.1 & 1.8 \\
\hline Religious Studies & 1.8 & 3.2 & 1.8 \\
\hline Communications & 2.4 & 4.0 & 1.7 \\
\hline Education/Speech Pathology & 3.3 & 5.6 & 1.7 \\
\hline Sociology/Social Work & 4.9 & 8.2 & 1.7 \\
\hline Physical Education & 1.4 & 2.1 & 1.5 \\
\hline Anthropology & 1.6 & 2.0 & 1.3 \\
\hline Foreign Languages & 2.0 & 2.5 & 1.3 \\
\hline English & 7.5 & 8.3 & 1.1 \\
\hline Economics & 5.0 & 4.9 & 1.0 \\
\hline Art & 4.6 & 4.5 & 1.0 \\
\hline Photography & 0.4 & 0.4 & 1.0 \\
\hline Agriculture & 1.8 & 1.6 & 0.9 \\
\hline Architecture & 0.7 & 0.6 & 0.9 \\
\hline Geography & 1.2 & 1.1 & 0.9 \\
\hline Psychology & 3.8 & 3.4 & 0.9 \\
\hline Engineering & 5.3 & 4.2 & 0.8 \\
\hline Health/Community Services & 1.3 & 1.0 & 0.8 \\
\hline Music & 1.7 & 1.4 & 0.8 \\
\hline Philosophy & 3.0 & 2.1 & 0.7 \\
\hline Political Science & 2.9 & 1.9 & 0.7 \\
\hline Geosciences & 1.4 & 0.8 & 0.6 \\
\hline Mathematics/Statistics & 2.1 & 1.1 & 0.5 \\
\hline Biology & 8.2 & 3.4 & 0.4 \\
\hline Nursing & 0.8 & 0.3 & 0.4 \\
\hline Theater Arts & 2.8 & 1.0 & 0.4 \\
\hline Physics & 2.2 & 0.8 & 0.4 \\
\hline Construction Management & 0.7 & 0.2 & 0.3 \\
\hline Management & 5.4 & 1.8 & 0.3 \\
\hline Finance/Marketing & 3.3 & 0.7 & 0.2 \\
\hline Accounting/Mngmt. Science & 1.5 & 0.1 & 0.1 \\
\hline Chemistry & 1.4 & 0.2 & 0.1 \\
\hline
\end{tabular}


subject allocation to reflect subject demand groups subjects in four broad categories (see tables 4 and 5).

\section{Conclusion}

With the cost of books increasing 50 percent during the five-year time span of this study, and with no end in sight, it becomes most obvious that subject allocations cannot continue to be based on precepts unsupported by the actual demand for materials. Classical notions of need must give way to practical utilization. Historically, library collection developers " ... simply relied on their genuine passion for literature and inbred instinct for what was 'right' when collecting."13 G. Edward G. Evans's lament that "Unfortunately, things have not changed that much in 35 years" remains largely true today. ${ }^{14}$ These "soft," nonanalytical approaches to collection development have positioned academic libraries in the unenviable position of "at times been called the financial 'black hole,' a unit of campus capable of expending all the resources sent its way, yet remaining with a crucial need for more acquisitions dollars," a roll that libraries can ill-afford to play with the current and increasing emphasis on accountability. ${ }^{15}$

Universities are now facing a new pragmatism in justifying the expenditure of funds, and academic library funding is no exception. Despite the emergence of a plethora of electronic alternatives to traditional print resources, the library is far from exclusively a "virtual" environment. Libraries will continue to be, in the words of James H. Billington, Librarian of Congress, " ... locations where both the new technologically dispensed information and the old knowledge repositories of books are present in the same place."16 Monographs now and into the twenty-first century will represent a major encumbrance of funding for library resources.

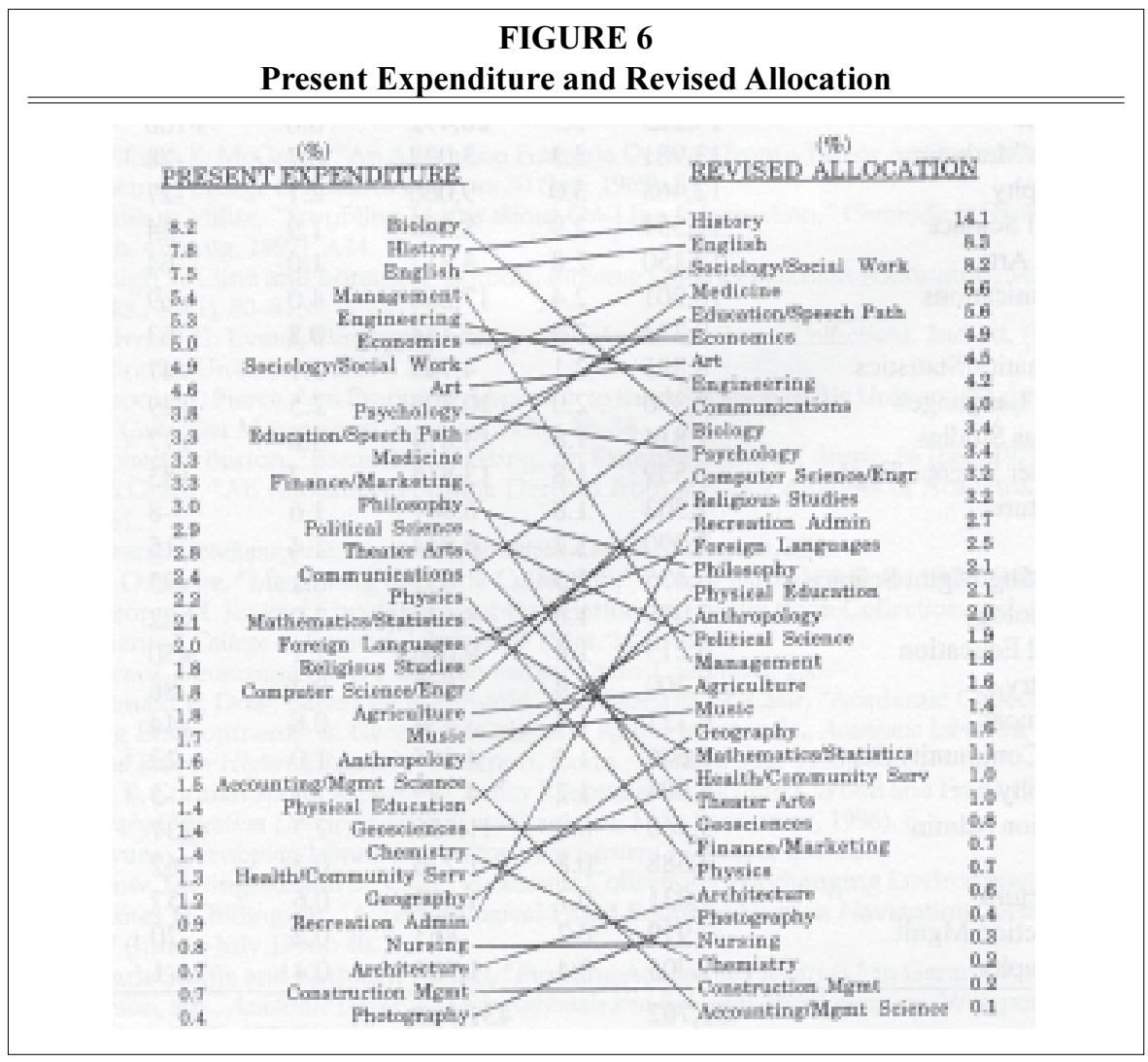


Library collection developers must embrace a new pragmatism in discriminate funding for monographs. Arbitrary standards for funding levels, inherited from historical allocation decisions and subsequently leveraged by faculty pressures, must give way to quality-based planning, grounded in an assessment of resources in demand by subject. ${ }^{17}$ Circu- lation appears to be the variable most representative of the true measure of usage (demand) of monographs. Academic libraries should consider experimenting with the allocation model and should explore further the utility of circulation as a prime parameter in the allocation by subject of funding for library monographs.

\begin{tabular}{|c|c|c|c|c|c|}
\hline \multicolumn{6}{|c|}{$\begin{array}{c}\text { TABLE } 4 \\
\text { Change in Allocation } \\
\end{array}$} \\
\hline Subject & $\begin{array}{c}\text { Present } \\
\text { Expenditure } \\
\text { Dollars }\end{array}$ & $\%$ & $\begin{array}{l}\text { Revised } \\
\text { Allocation } \\
\text { Dollars }\end{array}$ & $\%$ & $\%$ Change \\
\hline Biology & 34,998 & 8.2 & 14,678 & 3.4 & -59 \\
\hline History & 33,490 & 7.8 & 60,870 & 14.1 & +82 \\
\hline English & 32,255 & 7.5 & 35,831 & 8.3 & +10 \\
\hline Management & 23,141 & 5.4 & 7,771 & 1.8 & -66 \\
\hline Engineering & 22,694 & 5.3 & 18,131 & 4.2 & -20 \\
\hline Economics & 21,237 & 5.0 & 21,153 & 4.9 & 0 \\
\hline Sociology/Social Work & 20,862 & 4.9 & 35,400 & 8.2 & +70 \\
\hline Art & 20,677 & 4.6 & 19,427 & 4.5 & -0.2 \\
\hline Psychology & 19,097 & 3.8 & 14,678 & 3.4 & -10 \\
\hline Education/Speech Path & 14,247 & 3.3 & 24,175 & 5.6 & +69 \\
\hline Medicine & 14,225 & 3.3 & 28,492 & 6.6 & +100 \\
\hline Finance/Marketing & 13,981 & 3.3 & 3,022 & 0.7 & -78 \\
\hline Philosophy & 12,468 & 3.0 & 9,066 & 2.1 & -27 \\
\hline Political Science & 12,354 & 2.9 & 8,202 & 1.9 & -34 \\
\hline Theater Arts & 12,150 & 2.8 & 4,317 & 1.0 & -64 \\
\hline Communications & 10,201 & 2.4 & 17,268 & 4.0 & +69 \\
\hline Physics & 9,234 & 2.2 & 3,454 & 0.8 & -63 \\
\hline Mathematics/Statistics & 8,885 & 2.1 & 4,749 & 1.1 & -47 \\
\hline Foreign Languages & 8,390 & 2.0 & 10,793 & 2.5 & +29 \\
\hline Religious Studies & 7,814 & 1.8 & 13,814 & 3.2 & +77 \\
\hline Computer Science/Engr & 7,539 & 1.8 & 13,814 & 3.2 & +83 \\
\hline Agriculture & 7,503 & 1.8 & 6,907 & 1.6 & -8 \\
\hline Music & 7,090 & 1.7 & 6,044 & 1.4 & -15 \\
\hline Accounting/Mgmt Science & 6,475 & 1.5 & 432 & 0.1 & -93 \\
\hline Anthropology & 7,058 & 1.6 & 8,634 & 2.0 & +22 \\
\hline Physical Education & 6,213 & 1.4 & 9,066 & 2.1 & +50 \\
\hline Chemistry & 6,200 & 1.4 & 863 & 0.2 & -86 \\
\hline Geosciences & 6,121 & 1.4 & 3,454 & 0.8 & -44 \\
\hline Health/Community Serv & 5,606 & 1.3 & 4,317 & 1.0 & -23 \\
\hline Geography & 4,994 & 1.2 & 4,749 & 1.1 & -5 \\
\hline Recreation Admin & 3,460 & 0.9 & 11,656 & 2.7 & +237 \\
\hline Nursing & 3,388 & 0.8 & 1,276 & 0.3 & -62 \\
\hline Architecture & 3,031 & 0.7 & 1,295 & 0.6 & -57 \\
\hline Construction Mgmt & 2,919 & 0.7 & 863 & 0.2 & -70 \\
\hline Photography & 1,705 & 0.4 & 1,727 & 0.4 & -1 \\
\hline Total & 431,702 & & 431,702 & & \\
\hline
\end{tabular}


TABLE 5

Categories of Allocation Changes

\begin{tabular}{llrl}
\hline Increases 50\%+ & Reductions 50\%+ \\
\hline+237 & Recreation Administration & -93 & Accounting/Mgmt Science \\
+100 & Medicine & -86 & Chemistry \\
+83 & Computer Science/ Engineering & -87 & Construction Mgmt \\
+82 & History & -78 & Finance/Marketing \\
+70 & Sociology & -66 & Management \\
+77 & Religious Studies & -64 & Theater Arts \\
+69 & Communications & -63 & Physics \\
+69 & Education & -59 & Biology \\
+50 & Physical Education & -57 & Architecture \\
& & & \\
Increases/Reductions 10\%-50\% & Increases/Reductions $<10 \%$ \\
\hline+29 & Foreign Languages & 0 & Art \\
+10 & English & 0 & Economics \\
-15 & Music & -1 & Photography \\
-20 & Engineering & -5 & Geography \\
-23 & Health/Comm Services & -8 & Agriculture \\
-27 & Philosophy & -10 & Psychology \\
-34 & Political Science & & \\
-44 & Geosciences & & \\
-47 & Mathematics & & \\
\hline
\end{tabular}

\section{Notes}

1. William E. McGrath, "An Allocation Formula Derived from a Factor Analysis of Academic Departments," College \& Research Libraries 30 (Jan. 1969): 52.

2. William Miller, "Troubling Myths about On-Line Information," Chronicle of Higher Education 43, no. 47 (Aug. 1997): A44.

3. Hugh F. Cline and Loraine T. Sinnott, Building Library Collections (Lexington, Mass.: Lexington Bks., 1981), 80-81.

4. Edward G. Evans, Developing Library and Information Center Collections, 2nd ed. (Littleton, Colo.: Libraries Unlimited, 1987), 265.

5. Thomas J. Pierce, "An Empirical Approach to the Allocation of the University Library Book Budget," Collection Management 2 (spring 1978): 39-58.

6. Robert E. Burton, "Formula Budgeting: An Example," Special Libraries 66 (Feb. 1975): 61-67.

7. McGrath, "An Allocation Formula Derived from a Factor Analysis of Academic Departments," 61.

8. Evans, Developing Library and Information Center Collections, 234.

9. E. O. Stone, "Measuring the Book Collection," Library Journal 66 (June 1941): 941.

10. George M. Jenks, "Circulation and Its Relationship to the Book Collection and Academic Departments," College \& Research Libraries 37 (Mar. 1976): 151.

11. Evans, Developing Library and Information Center Collections, 235.

12. Ronald F. Dow, Salvatore Meringolo, and Gloriana St. Clair, "Academic Collections in a Changing Environment," in Gerard McCabe and Ruth Person, eds., Academic Libraries, Their Rationale and Role in Higher Education (Westport, Conn.: Greenwood, 1995), 109.

13. G. E. Gorman and B. R. Howes, "Policy Rationale," in Richard J. Wood and Frank Hoffmann, eds., Library Collection Development Policies (Lanham, Md.: Scarecrow, 1996), 8.

14. Evans, Developing Library and Information Center Collections, 234-35.

15. Dow, Meringolo, and St. Clair, "Academic Collections in a changing Environment," 109.

16. James H. Billington, "A Technological Flood Requires Human Navigation," American Libraries 27 (June-July 1996): 40.

17. Carla Stoffle and Kathleen Weibel, "Funding Academic Libraries," in Gerard McCabe and Ruth Person, eds., Academic Libraries, Their Rationale and Role in Higher Education (Westport, Conn.: Greenwood, 1995), 125-26. 